\title{
A Study on Herbal Drugs Utilization in Health Care Students
}

\author{
Nabila Perveen ${ }^{1}$, Naeem Hasan Khan ${ }^{2 *}$, Azmi Sarriff ${ }^{1}$ \\ 'Unit of Clinical Pharmacy, School of Pharmaceutical Sciences, Universiti Sains Malaysia (U.S.M.), Minden, Penang, MALAYSIA. \\ ${ }^{2}$ Faculty of Pharmacy, AIMST University, Bedong, Kedah, Darul Aman (D.A.), MALAYSIA.
}

\begin{abstract}
Objective: To investigate the herbal drugs utilization by health care students at AIMST University, Kedah D.A., Malaysia. Method: Analysis was carried out by using a Software Package for Statistical Analysis, Version 20. A total of 801 health care students were interviewed. Results: A total of 801 healthcare students were interviewed. The result showed that 796 (99.5\%) used herbal drugs while $5(0.5 \%)$ were not using herbal drugs. The male respondents were $229(100.0 \%)$ and female 567 (99.1\%) were utilized herbal drugs $28.8 \%, 71.2 \%$ respectively. The ethnicity showed $541(99.3 \%)$ and used herbal drugs $68.0 \%$ more as compare to other races. The highest utilization of herbal drugs was $75.4 \%$ within the age groups of $21-25$ years. The faculty of pharmacy respondents 321 (99.4\%) utilized herbal drugs $40.3 \%$ more as compare to other faculties. The third-year respondents $277(99.3 \%)$ showed more utilization of herbal drugs $34.8 \%$. Mostly students respondent were living in-campus 588 (99.3\%) utilized herbal drugs $73.9 \%$. Mostly respondents used herbal drugs in cough and common cold than headache, diarrhoea, common flue, fever/ chill and muscular pain. Most of respondents agreed upon mild illness 436 (54.4\%), economics cost $390(48.7 \%)$, and familiar with treatment option 348
\end{abstract}

(43.4\%). Conclusion: The herbal drugs are popular self-treatment remedies among health care students.

Key words: Herbal drugs, health care students, ethnicity, common cold and cough, SPSS 20.

Key message: It is deeply expected that this submitted original article will occupy the place in your esteemed journal. You are, as an editor, humbly requested to kindly accept and send the acceptance acknowledgement in early hours. Thanking you in advance for favourable consideration.

\section{Correspondence:}

Naeem Hasan Khan, Faculty of Pharmacy, AIMST University, Bedong, Kedah, Darul Aman (D.A.), MALAYSIA.

Phone: 0060169372470

Email: naeemhshirazi@hotmail.com

DOI: 10.5530/jyp.2018.10.23

\section{INTRODUCTION}

Home to some of the world's heavy rainforests, Malaysians have boosted remarkable biodiversity with a great range of plant species. ${ }^{1}$ The Malaysian herbal product market is experiencing a tremendous growth due to intense public interest in the use of crude plant-based products as medications.,3 More people are turning to herbal products as an alternative to the conventional therapeutic medicine. Malaysians consume approximately RM1.2 billion worth of imported herbal products annually., According to recent estimate by the World Health Organization (WHO), more than 3.5 billion people in the developing countries including Malaysia are relying on plants to treat various ailments. ${ }^{6}$ The Statistics Department Government of Malaysia in 1996 reported that a total import of medicinal plants amounting to RM 93.4 million in 1986, gradually increased to RM 264.8 million in 1996. For the period from January to November 2003, the Malaysian Pharmaceutical market was estimated to be about RM 1.84 billion (U.S. \$ 484 million), registering a growth of $5.5 \%$ over the corresponding period of 2003 . The market for herbal remedies was estimated to be above RM 2 billion (U.S. 530 million \$). It is estimated that about 2700 products are registered by Drug Control Authority, with more than 10,000 traditional / herbal products. Malaysian rain forests support more than 12,000 plant species out of which 2000 species have been reported for medicinal value. The traditional medicine presented in pharmaceutical form will require registration to National Pharmaceutical Control Bureau and today about 17,000 products have been registered. ${ }^{7}$ In Malaysia, total import of pharmaceutical and natural products was RM 2712 million and export was RM 496 million. ${ }^{8}$ In the year 1997, Malaysians spent about RM 2.0 billion on herbal medicines. This amounts to about RM 45.00 spent on herbals / herbal drugs per person per year in the United States compared to about RM 91.00 per person per year in Malaysia taking into account populations of 273 million and 22 million respectively. ${ }^{2}$ Herbal drugs are the most frequently used $(49.4 \%)$ by adult patients in Malaysia..$^{910}$ In 1999, more than 8000 herbal products were registered with the Ministry of Health, Malaysia. This illustrated the potential of the herbal market in Malaysia. Moreover, the general public was also accessed in connection with the utilization of herbal drugs., ${ }^{41-14}$ The objective of the present study is to understand and evaluate the herbal drugs utilization by health care students, through reliable and valid questionnaire and to determine the socio-demographic characteristics against various indications/illness from the Faculties of Pharmacy, Medicine, Dentistry, Nursing and Physiotherapy at AIMST University, Bedong, Kedah Darul Aman, Malaysia.

\section{Ethical approval}

The joint committee of School of Pharmaceutical Sciences, USM, Penang - Lam Wah Ee Hospital, Penang on clinical studies approved the protocol of this study with reference letter No. USM-HLWE/ IEC/2011 (0016) on 30.06.2012. The study was also registered with National Medical Research Registry (NMRR) and was approved by Medical Research \& Ethics Committee (MREC), National Medical Research Register Malaysia (NMRR Reference I.D. 10124 (Nabila Perveen C/O Azmi Sarriff) on 14.10.2011.

\section{METHODS}

In current study cross sectional approach by non-probability sampling was adopted; using self-administered questionnaire for health care 
students. In this study, Mann-Whiteny $\mathrm{U}$ and Kruskal-Wallis tests were applied to variables with two or more independent variables. Variables used in this study were divided as dependent variable and independent variable. The survey was carried out from the respondents who were at the age of 18 years and above. Moreover, respondents contributed meaningfully and effectively towards the study. Respondents were surveyed by self-interview (one to one interview) and by distribution. Written consent was also obtained from the respondents who participated in the study as an ethical requirement. The sample size was calculated on the basis of utilization of herbal drugs. The aim of the calculation was to determine an adequate sample size to estimate population based sample size with a good precision. ${ }^{15}$ In the sample size calculation for the present study, the parameters which were necessary to consider; indicator percentage; margin of error; confidence level, population size and critical value for the confidence level. The indicator percentage was assumed (0.50); margin of error was kept at $5 \%$; which is the amount of admissible error. Thus, for lower margin of error, the larger sample size is required. ${ }^{15}$

Data analysis was started after data collection, screened and input in a computer program. In present study, Statistical Package for the Social Sciences (SPSS) 20 was used for quantitative data analysis. Cross sectional study was adopted for present study. Data for the study was gathered from two main sources, primary and secondary. The primary data was collected through questionnaires by self-interviews/question-answer session (one to one interview) and by distribution of questionnaires to respondents. The secondary data for the study included reports, project documents, journals, magazines. In addition, information from the internet was also included in secondary database.

The total number of health care students at AIMST University from Faculties of Medicine, Pharmacy, Dentistry, Nursing, Physiotherapy were around 3000 (H.R., AIMST University (2011). So, the projected sample size of respondents (health care students) was around 3000. Based upon the population size of 3000 and $95 \%$ of confidence level with 5\% error of margin, the sample size calculated was 341 (based on above cited formula and equation). The total number of respondents surveyed for this study was 801 (health care students).

\section{RESULTS}

The number of female respondents were 572 (71.4\%) than male respondents $229(28.6 \%)$ as shown in Table 1. The respondents were Chines 545 (68.0\%) highest in number. Concerning age group 21- 25 (years) were participated more. The pharmacy student's respondents 323 (40.3\%) were highest in number. The student respondents were participated mostly from year three and living in-campus. Indian Malaysian health care students were $210(26.2 \%)$. The Malay students were lowest $33(4.1 \%)$. That might be explained that the area of survey, Chinese Malaysians health care students were more, followed by Indian Malaysians among other races. The Malay health care students at AIMST University were much less as compared to the other races.

The survey showed, health care student respondents were from Medicine 221 (27.6\%), Pharmacy 323 (40.3\%), Dentistry 170 (21.2\%), Nursing 34 (4.2\%) and Physiotherapy 53(6.6\%). The difference might be explained as the varying quantity of health care students in various faculties and moreover, the easy availability of individuals during the survey/ semesters or in the hostels of AIMST University. The Table 1 further explained, the health care students from the third year (from all faculties) were more involved 279 (34.8\%), followed by the students of year fourth 187 (23.3\%). Mostly the health care student respondents involved in the survey were Malaysians, living in-campus 592 (73.9\%) as compared to the private (day scholar) status 209 (26.1\%).

The respondents were allowed to answer more than one from Table 2. The mild illness, economic cost and familiar with treatment were major factors that student respondents had utilized herbal drugs. From data collected, respondents strongly agreed for economic cost 93 (11.6\%) and simply agreed 390 (48.7\%). Regarding the mild illness respondents strongly / simple agreed 606 (69\%) for utilization of herbal drugs. Familiar with the treatment options, respondents strongly agreed 384 (43.4\%) was major factor for utilization of herbal drugs among health care students. Table 3 indicated various indication/illness for which the herbal drugs were utilized by health care students in various groups.

Table 4 described the accumulated results of inferential analysis in the form of summary sheet, gender, ethnicity, professional year, faculties and living status of respondents about the utilization of herbal drugs in various indications. The total number of respondents was 801 while only five (5) female respondents declined the use the herbal drugs. Male students responded were $229(100.0 \%)$ and females were 567 (99.1\%) and utilization of herbal drugs was $28.8 \%$ and $71.2 \%$ respectively with the results of $\chi 2$ and $P$ values were 2.014 and 0.185 . Malays + others (non-Malaysian health care students from Indonesia, India, Thailand, Pakistan) were 46 (100.0\%), Malaysian Chinese 541 (99.3\%), Malaysian Indians $209(99.5 \%)$ and utilization was $68.0 \%$ and $26.3 \%$ with $\chi 2$ value was 0.469 and $\mathrm{P}$ value came to be 0.791 . Results showed that respondents from year three, 277 (99.3\%) were more involved in utilization of herbal drugs (34.8\%). Here the $\chi 2$ value was 5.187 and $P$ value came to be 0.269 .

\begin{tabular}{|c|c|c|}
\hline & & $\begin{array}{c}\text { Students participated } \\
\mathrm{n}(\%)\end{array}$ \\
\hline \multirow[t]{2}{*}{ Sex } & Male & $229(28.6)$ \\
\hline & Female & $572(71.4)$ \\
\hline \multirow[t]{4}{*}{ Race } & Malay & $33(4.1)$ \\
\hline & Malaysian Chinese & $545(68.0)$ \\
\hline & Malaysian Indians & $210(26.2)$ \\
\hline & Others (non-Malaysian)* & $13(1.6)$ \\
\hline \multirow{3}{*}{$\begin{array}{c}\text { Age in } \\
\text { groups(years) }\end{array}$} & $16-20$ & $184(23.0)$ \\
\hline & $21-25$ & $602(75.2)$ \\
\hline & $26-30$ & $15(1.9)$ \\
\hline \multirow[t]{2}{*}{ Nationality } & Malaysian & $797(99.5)$ \\
\hline & Others & $04(0.5)$ \\
\hline \multirow[t]{5}{*}{ Faculties } & Medicine & $221(27.6)$ \\
\hline & Pharmacy & $323(40.3)$ \\
\hline & Dentistry & $170(21.2)$ \\
\hline & Physiotherapy & $53(6.6)$ \\
\hline & Nursing & $34(4.2)$ \\
\hline \multirow[t]{5}{*}{ Year of study } & Year one & $97(12.5)$ \\
\hline & Year two & $128(16.0)$ \\
\hline & Year three & $279(34.8)$ \\
\hline & Year four & $187(23.3)$ \\
\hline & Year five & $110(13.7)$ \\
\hline \multirow[t]{2}{*}{ Living status } & Private & $209(26.1)$ \\
\hline & In-campus & $592(73.9)$ \\
\hline
\end{tabular}

$\mathrm{n}=$ number of respondents participants, $\%=$ percentage of respondents participated, ${ }^{*}=$ non-Malaysians from Indonesia, India, Thailand, Pakistan. 


\begin{tabular}{|c|c|c|c|c|c|c|c|}
\hline & \multirow{2}{*}{$\begin{array}{c}\text { Reason } \\
(\mathrm{n} / \%)\end{array}$} & \multicolumn{6}{|l|}{ Response } \\
\hline & & $\begin{array}{c}\text { Strongly agree } \\
(\mathrm{n} / \%)\end{array}$ & $\begin{array}{l}\text { Agree } \\
(\mathrm{n} / \%)\end{array}$ & $\begin{array}{l}\text { Undecided } \\
\text { (n/\%) }\end{array}$ & $\begin{array}{l}\text { Disagree } \\
(n / \%)\end{array}$ & $\begin{array}{l}\text { Strongly disagree } \\
(\mathrm{n} / \%)\end{array}$ & $\begin{array}{c}\text { No reply } \\
\text { (n/\%) }\end{array}$ \\
\hline Economic cost & $83(10.4)$ & $93(11.6)$ & $390(48.7)$ & $160(20.0)$ & $92(11.5)$ & $19(2.4)$ & $47(5.9)$ \\
\hline Time saving & $78(9.7)$ & $85(10.6)$ & $258(32.5)$ & $219(27.3)$ & $147(18.4)$ & $20(2.5)$ & $72(9.0)$ \\
\hline Familiar with treatment option & $82(10.2)$ & $104(13.0)$ & $348(43.4)$ & $200(25.0)$ & $56(7.0)$ & $9(1.1)$ & $84(10.5)$ \\
\hline Quick relief & $77(9.6)$ & $81(10.1)$ & $244(30.5)$ & $264(33.0)$ & $115(14.4)$ & $16(2.0)$ & $81(10.1)$ \\
\hline Condition did see doctor & $77(9.6)$ & $96(12.0)$ & $301(37.6)$ & $234(29.2)$ & $86(10.7)$ & $5(0.6)$ & $79(9.9)$ \\
\hline Any other, please specify: & $91(11.4)$ & $18(2.2)$ & $9(1.1)$ & $39(4.9)$ & $1(0.1)$ & $2(0.2)$ & $732(91.4)$ \\
\hline
\end{tabular}

$\mathrm{n}=$ number of respondents participated, $\%=$ percentage of respondents participated, privacy ${ }^{*}=$ (free from unwanted or undue intrusion or disturbance in one's private life or affairs)

\begin{tabular}{|c|c|c|}
\hline $\begin{array}{c}\text { Group } \\
\text { No. }\end{array}$ & Disease/ indication/illness & Detail of disease/ indication/illness \\
\hline 1. & All Pains & Headache, muscular pain, ear pain, gastric pain (all coded) \\
\hline 2. & All pains + Respiratory & Headache, muscular pain, ear pain, gastric pain, Cough, common flu, chills (all coded) \\
\hline 3. & All pains + Respiratory + fever & $\begin{array}{l}\text { Headache, muscular pain, ear pain, gastric pain, Cough, common flu, chills }+ \text { fever } \\
\text { (all coded) }\end{array}$ \\
\hline 4. & All pains + Respiratory + fever + others & $\begin{array}{l}\text { Headache, muscular pain, ear pain, gastric pain, common flu, chills }+ \text { fever, infections, } \\
\text { allergies, ease in labour (all coded) }\end{array}$ \\
\hline 5. & All pains + Respiratory +fever + G.I.T. + others & $\begin{array}{c}\text { Headache, muscular pain, ear pain, gastric pain, common flu, chills + fever, infections, } \\
\text { allergies, ease in labour (all coded) }\end{array}$ \\
\hline
\end{tabular}

Faculty of Pharmacy respondents were 321 (99.4\%) and the utilization of herbal drugs was $40.3 \%$ more than other Faculties. The $\chi 2$ value was 2.924 and $\mathrm{P}$ - values was 0.571 . In the private/in-campus respondents were 208 (99.5\%) and 588 (99.3\%) while utilization was $26.1 \%$ and $73.9 \%$ respectively. The $\chi^{2}$ value was 0.097 and $P$ value was 0.610 . In the age group of 21-25 years of respondents was 600 (99.7\%) was utilized herbal drugs $75.4 \%$ highest as compared to other age groups. The $\chi^{2}$ value was 3.925 and $\mathrm{P}$ value was 0.141 .

Table 5 explained about the response for utilization of herbal drugs in various indications. The utilization of herbal drugs was $26.9 \%$ and $33.0 \%$ in one / five indications/illness respectively in male student respondents. The female student respondent's utilization was $73.1 \%$ and $67.0 \%$ in one / five indication/illness. The utilization among Malaysian Chinese was $70.5 \%$ and $63.1 \%$ in one / five respectively. Regarding faculties, it revealed that response from Faculty of Pharmacy was higher as compared to others. The respondents from Faculty of Medicine utilized $33.3 \%$ and $24.7 \%$ in one / five indications/illness respectively. In the age group of 21-25 years, the respondents' utilization was $71.8 \%$ and $73.8 \%$ in one / five respectively.

Table 6 showed no association among gender, ethnicity, living status and age with the utilization of herbal drugs. As almost all the health care student respondents utilized herbal drugs.

\section{DISCUSSION}

The study was a part of representative of Malaysian population. The survey study was carried out at the Faculties of Medicine, Pharmacy, Dentistry, Nursing and Physiotherapy of AIMST University, Bedong, Kedah D.A. Among 801 student respondents, the utilization of herbal drugs was $99.5 \%$. Among health care student respondents, the female respondents were higher $(71.1 \%)$ as compared to male respondents (28.9\%) from different faculties. The total number of respondents was 801 out of which only five (5) respondents declined the use of herbal drugs. The student respondents strongly agreed upon mild illness, cost effectiveness and familiar with the treatment options.

The utilization of herbal drugs in respondents was higher in cough and common cold and less utilization in headache and common flu was comparatively. Respondents utilized herbal drugs in cases of diarrhea, muscular pain and for skin allergic reactions. The respondents utilized herbal drugs that might have been due to heavy academic daily load. The indication of diarrhea might be due to irregular food or possible food poisoning that might be infections. Moreover, the respondents (living in hostels or day scholars) usually had their meals 3-6 times in a day at the university cafeteria which might be one of reason to get some type of food poisoning. The gastric pain might be from some food or even stress of studies. The fungal infection cases might be from the joint toilets utilized by the respondents. Different allergic reactions might be due 


\begin{tabular}{|c|c|c|c|c|c|c|}
\hline Variables & & $\begin{array}{c}\text { Response } \\
\text { n (\%) }\end{array}$ & $\begin{array}{l}\text { Herbal drugs } \\
\text { utilization (\%) }\end{array}$ & df & $x^{2}$ value & P-value \\
\hline \multicolumn{7}{|l|}{ Sex } \\
\hline & Male & 229 & 28.8 & 1 & 2.014 & 0.185 \\
\hline & Female & 567 & 71.2 & & & \\
\hline \multicolumn{7}{|l|}{ Ethnicity } \\
\hline & Malays + others* & 46 & 5.8 & 2 & 0.469 & 0.791 \\
\hline & Malaysian Chinese & 541 & 68.0 & & & \\
\hline & Malaysian Indians & 209 & 26.3 & & & \\
\hline \multicolumn{7}{|l|}{ Years of } \\
\hline study & $1^{\text {st }}$ year & 95 & 11.9 & 4 & 5.187 & 0.269 \\
\hline & $2^{\text {nd }}$ year & 127 & 16.0 & & & \\
\hline & $3^{\text {rd }}$ year & 277 & 34.8 & & & \\
\hline & $4^{\text {th }}$ year & 187 & 23.5 & & & \\
\hline & $5^{\text {th }}$ year & 110 & 13.8 & & & \\
\hline \multicolumn{7}{|l|}{ Faculties } \\
\hline & Medicine & 219 & 27.5 & 4 & 2.924 & 0.571 \\
\hline & Pharmacy & 321 & 40.3 & & & \\
\hline & Dentistry & 170 & 21.4 & & & \\
\hline & Physiotherapy & 52 & 6.5 & & & \\
\hline & Nursing & 34 & 4.3 & & & \\
\hline \multicolumn{7}{|c|}{ Living status } \\
\hline & Private & 208 & 26.1 & 2 & 0.097 & 0.610 \\
\hline & In-campus & 588 & 73.9 & & & \\
\hline \multicolumn{7}{|l|}{ Age group } \\
\hline & $16-20$ years & 181 & 22.7 & 2 & 3.925 & 0.141 \\
\hline & $21-25$ years & 600 & 75.4 & & & \\
\hline & 26-30 years & 15 & 1.9 & & & \\
\hline
\end{tabular}

$\mathrm{n}=$ number of respondents response, $\%=$ percentage of herbal drugs utilized, $\mathrm{df}=$ degree of

freedom, $\chi^{2}=$ Pearson Chi- Square test, $\mathrm{P}$ value $=$ calculate by Pearson Chi- Square test,

* $=$ non-Malaysians from Indonesia, India, Thailand, Pakistan.

to environment and surroundings of the university. A few respondents utilized herbal drugs for constipation which might be due to food irregularities. The utilization of herbal drugs for muscular relaxation might be explained that the students get tired during regular academics and for the relaxation of body muscles, utilized these herbal drugs. ${ }^{18}$ There might be different explanations for allergies seemed to be, that most of above surveyed students were residing in the hostels (in- side the campus area at the AIMST university which was about $20 \mathrm{Km}$ away from the city center) and also because the students were dependent on herbal drugs utilization based upon the cheapness and easy availability. ${ }^{18}$

The co-relation was carried out between utilization of herbal drugs and various indications/illness. The total number of indications / illness were condensed from 16 to 5 for analysis reason as mentioned in Table 3. The female students were more likely to be users of herbal drugs. ${ }^{16-18}$ Not surprisingly, utilization of herbal drugs by different ethnic student groups varied widely that might be explained by cultural differences and the overall number of students in AIMST University. In this study, ethnicity was also a significant predictor of herbal drugs utilization. It was further explained about the response for utilization of herbal drugs in various indications/illness among student respondents. The male student respondent's utilization of herbal drugs was $26.9 \%$ and $33.0 \%$ in one and five indications/illness respectively. The female student respondents utilized herbal drugs more in one and five indications/illness as compared to male respondents. Regarding the ethnicity, Malaysian Chinese respondent utilization of herbal drugs was higher in than Malaysian Indian respondents while Malay respondents utilized herbal drugs least in one and five indication/illness. The Faculty of Pharmacy respondents was higher as compared to other faculties in utilization of herbal drugs. About the utilization of herbal drugs in different races in Malaysia, the Malaysian Chinese utilized more herbal drugs because the Chinese students in Malaysia thought to utilize herbal drugs more than other races. The student respondents answered to most of the questions designed in the questionnaire. But it was also observed, generally, that it was not an easy job to get information from Malaysian Chinese students about the herbal drugs utilization due to unexplained reasons. ${ }^{19-21}$

The binary logistic regression analysis for students was carried out but could not find any prominent results due to all students had utilized herbal drugs. Student respondents totally dependent on herbal drugs even though they are directly related to health care safety. This study had lack of information among the health care student respondents about the safe use of herbal drugs. 
Table 5: Utilization of herbal drugs in various indications/illness by health care students.

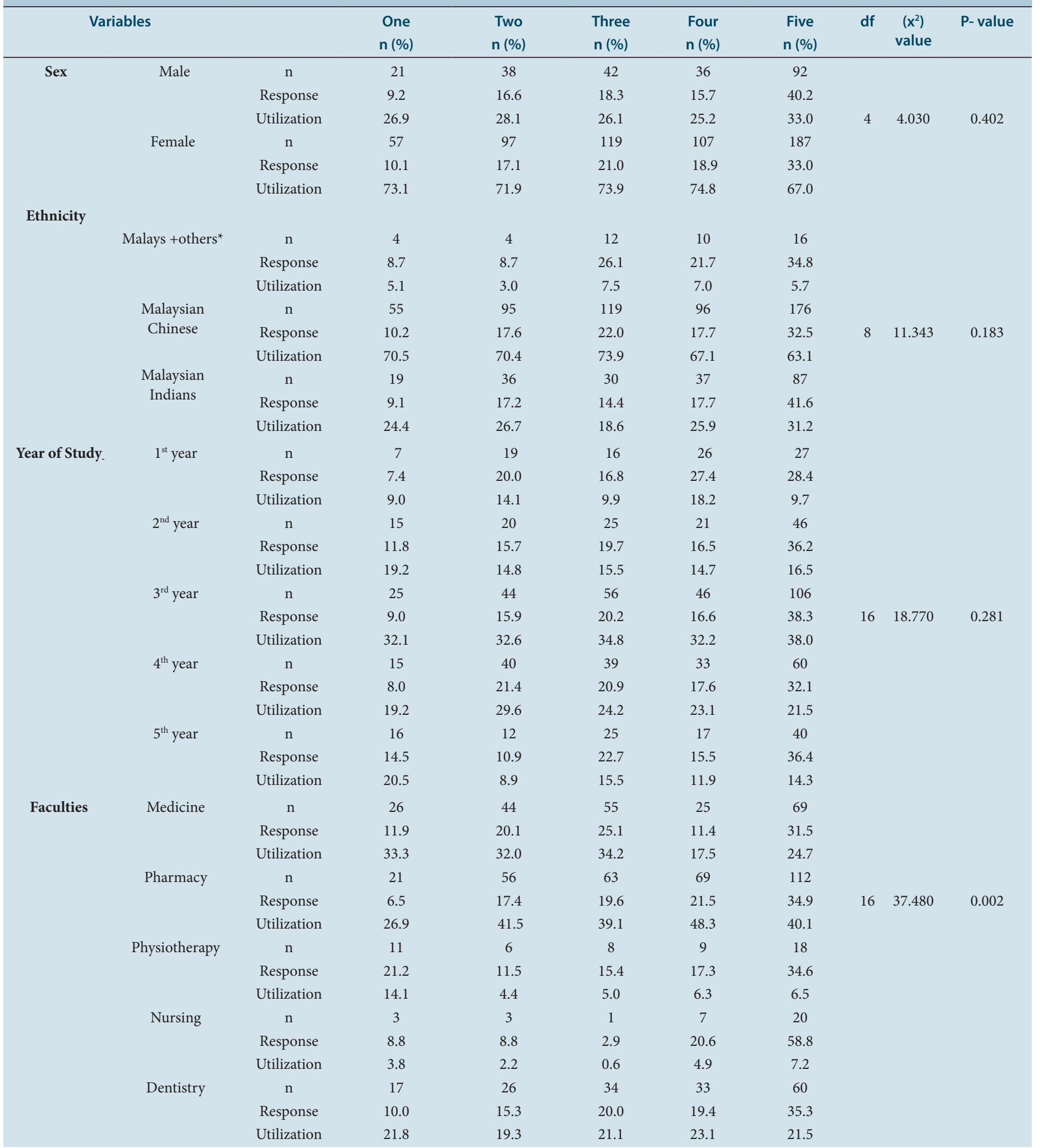




\begin{tabular}{|c|c|c|c|c|c|c|c|c|c|c|}
\hline \multicolumn{11}{|l|}{ Age Group } \\
\hline & $16-20$ years & $\mathrm{n}$ & 22 & 24 & 33 & 37 & 65 & & & \\
\hline & & Response & 12.2 & 13.3 & 18.2 & 20.0 & 35.9 & & & \\
\hline & & Utilization & 28.2 & 17.8 & 20.5 & 25.9 & 23.3 & & & \\
\hline & 21-25 years & $\mathrm{n}$ & 56 & 110 & 126 & 102 & 206 & & & \\
\hline & & Response & 9.3 & 18.3 & 21.0 & 17.0 & 34.3 & 8 & 9.697 & 0.287 \\
\hline & & Utilization & 71.8 & 81.5 & 78.3 & 71.3 & 73.8 & & & \\
\hline & 26-30 years & $\mathrm{n}$ & 0 & 01 & 2 & 4 & 8 & & & \\
\hline & & Response & 0.0 & 6.7 & 13.3 & 26.7 & 53.3 & & & \\
\hline & & Utilization & 0.0 & 0.7 & 1.2 & 2.8 & 2.9 & & & \\
\hline \multicolumn{11}{|l|}{ Living status } \\
\hline & private & $\mathrm{n}$ & 15 & 39 & 48 & 29 & 77 & & & \\
\hline & & Response & 7.2 & 18.8 & 23.1 & 13.9 & 37.0 & & & \\
\hline & & Utilization & 19.2 & 28.9 & 29.8 & 20.3 & 27.6 & 4 & 6.435 & 0.169 \\
\hline & In-campus & $\mathrm{n}$ & 63 & 96 & 113 & 114 & 202 & & & \\
\hline & & Response & 10.7 & 16.3 & 19.2 & 19.4 & 34.4 & & & \\
\hline & & Utilization & 80.8 & 71.1 & 70.2 & 79.7 & 72.4 & & & \\
\hline
\end{tabular}

Number of indications $=$ Table 1.3, $($ One - Five $)=$ indications/illness, $\%=$ herbal drugs utilization, $\mathrm{n}(\%)=$ number of respondents ant its percentage, $\mathrm{df}=\mathrm{degree}$ of freedom, $\chi^{2}$ value $=$ Pearson Chi-square test, $\mathrm{P}=$ calculated by Pearson Chi-square test,

${ }^{*}=$ non-Malaysians from Indonesia, India, Thailand, Pakistan.

Table 6: Binary logistic regression analysis for health care students

\begin{tabular}{|c|c|c|c|c|c|c|}
\hline \multirow[t]{2}{*}{ Variables } & & n (\%) & $\begin{array}{c}\operatorname{Exp}(\mathrm{B}) \\
\text { (OR) }\end{array}$ & $95 \% \mathrm{Cl}$ for & $\operatorname{Exp}(B)$ & P-value \\
\hline & & & & Lower & upper & \\
\hline \multirow[t]{2}{*}{ Sex } & Male & $229(100.0)$ & \multirow{2}{*}{16.261} & \multirow[b]{2}{*}{ - } & \multirow[b]{2}{*}{-} & \multirow{2}{*}{.995} \\
\hline & Female & $567(99.1)$ & & & & \\
\hline \multirow[t]{3}{*}{ Ethnicity } & Malays + others ${ }^{*}$ & $46(100.0)$ & \multirow{3}{*}{-.060} & \multirow{3}{*}{.151} & \multirow{3}{*}{5.857} & \multirow{3}{*}{.949} \\
\hline & Chinese & $541(99.3)$ & & & & \\
\hline & Indian & 209(99.5) & & & & \\
\hline \multirow[t]{2}{*}{ Living status } & Private & $209(26.1)$ & \multirow[b]{2}{*}{-.826} & \multirow[b]{2}{*}{.064} & \multirow{2}{*}{7.287} & \multirow{2}{*}{.752} \\
\hline & In-campus & $592(73.9)$ & & & & \\
\hline Age Groups & Group1 (16-20) & $181(98.4)$ & & & & \\
\hline \multirow[t]{2}{*}{ (years) } & Group2 (21-25) & $600(99.7)$ & \multirow[t]{2}{*}{-.382} & \multirow[t]{2}{*}{.032} & \multirow[t]{2}{*}{5.980} & \multirow[t]{2}{*}{.536} \\
\hline & Group3 (26-30) & $15(100.0)$ & & & & \\
\hline
\end{tabular}

$\mathrm{OR}=\operatorname{Exp}(\mathrm{B})$ expected odds ratio, $\mathrm{CI}=$ confidence interval for $\exp (\mathrm{B})$,

$\mathrm{P}=$ significant value, $\mathrm{n}(\%)=$ number of respondents response and percentage,

${ }^{*}=$ non-Malaysians from Indonesia, India, Thailand, Pakistan.

\section{CONCLUSION}

Among student respondents, female students were highly involved in herbal drugs utilization. Malaysian Chinese students utilized herbal drugs more than Malaysian Indian student respondents. The herbal drugs utilized were highest among third year student respondents with the age group of 21-25 years. The respondents from the Faculty of Pharmacy utilized with highest percentage of herbal drugs. Usually the respondents utilized herbal drugs more in one and five indications/ illness while it was less in two, three and four indications/illness. Individually respondents utilized herbal drugs more for cough and common cold, headache, diarrhea, common flu, fever and chills and muscular pain. The utilization of herbal drugs was observed towards mild illness, cost effectiveness and familiar with the treatment options. The student respondents declined to share the specified names of herbal drugs used and moreover, it was not a motion to compel the respondents. This research work was concluded to evaluate the utilization of herbal drugs in aspect of their usage among different groups in Malaysia. In doing so, it would also determine the driving force behind the intense public interest for herbal drugs utilization. The present practice of medicine still depends upon heavily on information obtained through ethno-pharmacological experiences. The popularity of herbal products was more associated with consumer's ability.

Further research has to be focused on utilization of herbal drugs to be carried out to evaluate the efficacy of the herbal drugs. Respondent's personal attributes and opinions influence their likelihood of using herbal 
drugs which might help health care providers and policy planners to identify the needs of additional guidance on their safe use. According to this study, the herbal drugs seemed to be effective and popular way of treatment among student respondents.

\section{ACKNOWLEDGEMENT}

Nil

\section{CONFLICT OF INTEREST}

The authors declare that there is no conflict of interest.

\section{SOURCE OF FUNDING}

The entire cost throughout the study period for Ph.D. degree was financed by the first author.

\section{REFERENCES}

1. Bodeker G. Health and beauty from the rainforest: Malaysian Traditions of Ramuan. Kuala Lumpur: 2009; Didier Millet. ISBN 978-981-4217-91-0.

2. Hussin $\mathrm{AH}$. Adverse effects of Herbs and Drug-Herbal interactions, Malay. J Pharm. 2001;1(2):39-44.

3. Ong HC, Nordiana M. Malay ethno-medico botany in Machang, Kelantan, Malaysia. Fitotherapia. 1999;70(5-1):502-13.

4. Siti ZM, Tahir A, Ida Farah A, Ami Fazlin SM, Sondi S, Azman AH, et al. Use of traditional and complementary medicine in Malaysia: A base line study. Comp Thera in Med Elsevier. 2009;17(5-6):292-9.

5. Ibrahim J. The scientific values of Malaysian Herbal Products. J Sains Kesihatan Malaysia. 2006;4(1):59-70. ISSN 1675-8161.

6. Samad, A. Warisan Perubatan Melayu, 2005; $2^{\text {nd }}$ edit., Dewan Bahasa and Pustaka, Kuala Lumpur, Malaysia.

7. South-south trading promotion programme Malaysia, International trade centre, March 2008
8. Department of statistics, (2006). Government of Malaysia.

9. Rosen IM, Christi P. Health and health care among house staff. J Internal Medicine. 2000;15(2):116-21.

10. Chan K. Some aspects of toxic contaminants in herbal medicines. Chemoshere. 2003;52:1361-71.

11. David M, Merita McCabe, Ricciardelli L, Yeow J, Daliza N, Noor Fazlee bt Mohd Hapidzal. Sociocultural influences on body dissatisfaction and body change behaviours among Malaysian adolescent. Body image. 2009;6(2):121-8.

12. Hasali MA, Saleem F, Akmal SA, Al-Qazaz HK, Farooqui M, Aljadhey $H$, et al. Assessment of general public perceptions towards traditional medicines used for aphrodisiac purpose in State of Penang, Malaysia. CompThera in Clin Practice Elsevier. 2012;18(4)257-60.

13. Muneer GB, Shahzad HS, Cho MN, Nur Hidaya BH. Perception and self- use of complementary and alternative medicine (CAM) among Malaysian dental students. Eur J Integ Med. 2012;4(1):e63-e9.

14. Zhari I, Noryayati I, Jaafar L. Malaysian Herbal Monograph. Vol. 1. Malaysian herbal monograph committee, 2001; Kuala Lumpur.

15. Naing L, Winn T, Rusli BN. Practical issues in calculating the sample size for prevalence studies. Arch Orofacial Scie. 2006;1:9-14.

16. Bartlett JEII, Kotrik JW, Higgins C. Organizational research: Determination appropriate sample size for survey search. Information Technology, Learning and Performance J. 2001;19(1):43-50.

17. Hosmer DW Jr, Lemeshow S, Sturdevant RX. Applied logical regression, third edition, Wiley 2013. ISBN 9780470582573.

18. Saw JT, Bahari MB, Ang HH, Lim UH. Potential drug-herb interaction with antiplatelet/anticoagulant drugs. Comp Thera in Clin Practice Elsevier. 2006;12(4):236-41.

19. Sneha S, Chabria A, Sujit SS. Pharmacy Students Knowledge and Attitude towards Herbal Medications. Inter J Pharm Teaching \& Practices. 2012;3(3):301-7.

20. Aziz AZ, Tey NP. Herbal medicines: Prevalence and predictors of use among Malaysian adults. Comp Thera in Medicine. 2009;17:44-50.

21. Bright $A$. Utilization of traditional herbal medicine and its role in health care delivery in Ghana: the case of wassa amenfi west district. A Thesis submitted to the Department of Geography and Rural Development, Kwame Nkrumah University of Science and Technology 2013. 